made at the present time. The first two lectures were delivered in March to girls from London secondary schools by Mr. C. C. Paterson, director of the Research Laboratories of the General Electric Co., Ltd., Wembley, and have now been issued by the Guild as a pamphlet (Pp. 20. 1s.) entitled "The Electron Liberated; its Industrial Consequences". They deal with the emission of electrons from hot and illuminated surfaces and the uses made of them in modern electrical engineering, in particular in the production of light. The mysterious dual character of the electron as a missile and a group of waves is not forgotten, and the necessity for more and better knowledge of its properties is insisted on. The Guild is to be congratulated on the inaugural lecturer, to whom thousands of electrical engineers listened with such pleasure on the subject last year. The sooner other schools can have the benefit of lectures of this type, the better it will be for our future citizens.

\section{Industrial Administration, at Loughborough College}

FacILITIES for training in industrial administration and management are now increasing in Great Britain, the latest development being that at Loughborough College, where a Department of Industrial Administration was inaugurated last year. The courses provided are of an intensive nature, extending over short periods, and the aim is to provide a kind of staff college for industry where executives may be given an insight into a larger range of administrative practice than they would be likely to obtain in the ordinary way. The scope of the new department is thus somewhat different from those now well established at the Manchester College of Technology, or the London School of Economics, which provide courses extending over one or two academic years. The facilities provided at Loughborough include week-end, ten-day and longer courses adapted to the degree of experience of those attending. Instruction includes lectures, organised reading, group discussions, personal discussion of individual problems and visits to works and offices. It is intended that the week-end courses should be confined to executives with practical experience in the same industry, and in the first instance, these are being provided for engineering executives and will deal with such special topics as costing, rate-fixing and progress control. In the prospectus of the Department, it is pointed out that the various courses are of especial value to ownermanagers who have not been able to acquire experience in other businesses, and to executives whose experience has been confined to a restricted field.

\section{Meteorology of the South Seas}

Apia Observatory, in Western Samoa, is under the control of the Department of Scientific and Industrial Research, New Zealand, and the work is directed by Mr. J. Wadsworth, formerly in the Meteorological Office, Air Ministry, who has recently presented his report for 1932 to the Observatory Board in the form of a compact and very clearly printed little volume of 114 pages. The report is a summary of observations in terrestrial magnetism, seismology, meteorology and atmospheric electricity. Synoptic weather charts were made on every day of the year, the data being collected by the wireless station at Apia from twenty observing stations in other groups of islands in the South Pacific, and some. times from passing ships. Since May 1932 a daily weather report has been exhibited at the Post Office and Customs House in Apia, at the request of local shipowners. Considering the small size of the staff, which consists of the director and two scientific assistants and four locally recruited clerks, the amount of work accomplished, especially on the purely meteorological side, seems highly satisfactory. Upper winds were measured with the aid of pilot balloons on seventy-eight occasions; the usual meteorological instruments were maintained, while in addition a Piché evaporimeter and a Wilson radio integrator were read daily at 9 a.m. The meteorological summaries are so detailed that a very clear idea can be formed of the weather experienced from day to day in this part of the South Seas; they include, also, less detailed climatological summaries from other groups of islands. An even fuller programme was contemplated, for arrangements were being made for re-conditioning and bringing into use a spectrohelioscope which was obtained on loan from Mount Wilson Observatory.

\section{Standardisation of Insecticides and Fungicides}

THE standardisation of insecticides and fungicides has for some years been a matter of discussion among both the users and manufacturers of these chemicals, and requests from farmers and growers that the content of active materials in these products should be guaranteed resulted in the publication by the Ministry of Agriculture of specifications of a number of those most generally in use (Advisory Leaflet No. 9). To meet the recent great development in the employment of insecticides and fungicides, a further publication has now been issued by the Ministry, namely, Bulletin 82, "Specifications and Methods of Analysis for Certain Insecticides and Fungicides" (London: H.M. Stationery Office. 3d. net). In this bulletin, the specifications already published have been brought up to date, and additional specifications for certain compounds such as copper fungicides, not previously dealt with, have been included. In addition, agreed methods of analysis, drawn up in connexion with the specifications, are supplied. Both specifications and analytical methods have been accepted by the Association of British Insecticide Manufacturers, the Government Laboratory, the National Farmer's Union and the Ministry of Agriculture. Purchasers are strongly advised to require a guarantee that materials supplied comply with these specifications, for, by so doing, they ensure that they obtain standard products of high quality.

\section{Lancashire Sea-Fisheries Research}

The report for 1932 (No. 41) on the Lancashire Sea-Fisheries Laboratory at the University of Liverpool (1933), edited by Dr. R. J. Daniel, is in 